\title{
HIGH COSTS FOR CO-OCCURRENCE OF NECK/SHOULDER AND LOW BACK DISORDERS IN SWEDEN
}

Johan Liwing, Karolinska Institutet, Dep Public Health, Div Occupational and Environmental Health, Stockholm, Sweden, Johan.Liwing@jokideer.se

Assoc.Prof. Christina Wiktorin, Karolinska Institutet, Dep Public Health, Div Occupational and Environmental Health, Stockholm, Sweden, Christina.Wiktorin@ki.se

Dr. Wilhelmus, JA Grooten, Karolinska Institutet, Dep Public Health, Div Occupational and Environmental Health, Norrbacka, Stockholm, Sweden \& Department Neurobiology, Caring Sciences and Society; Division of Physiotherapy, Huddinge, Sweden, Wim.Grooten@ki.se

Dr. Teresia Nyman, Karolinska Institutet, Dep Public Health, Div Occupational and Environmental Health, Stockholm, Sweden, Teresia.Nyman@ki.se

Prof. Magnus Svartengren, Karolinska Institutet, Dep Public Health, Div Occupational and Environmental Health, Stockholm, Sweden, Magnus.Svartengren@ki.se

\begin{abstract}
Aim: The aim of the present study was to analyse if the localization of unspecific back disorders influenced the yearly direct and indirect costs during a five year period; 1996 to 2001.

Methods: Based on the location and the recurrence of neck/shoulder disorders (NSD) and low back disorders (LBD) disorders, 2057 individuals were grouped into six different disorder groups and one control group without disorders. Direct costs were calculated using self-reported data on drug use, health care utilization and ergonomic interventions. Indirect costs were calculated using yearly collected individual register data on personal income and government compensation for sickness absence. The costs for each of the six groups with NSD and/or LBD were estimated by subtracting the costs in the control group from the costs in each disorder group with NSD/LBD. Adjustments were made for age, gender, and other diseases.
\end{abstract}


Johan LIWING, Christina WIKTORIN, Wilhelmus JA GROOTEN,

Teresia NYMAN and Magnus SVARTENGREN

Results: The indirect costs were ten times higher than the direct costs. The total average individual costs for the subjects with co-occurrence NSD and LBD was $\$ 6.000$ for the year 2001 . This was three to four times higher than for those with solely NSD or solely LBD. The largest increase in costs between 1996 and 2001 was seen in this group.

Conclusion: Further studies are required to identify which characteristics in work environment or in life style that causes recurrent and concurrent NSD and LBD.

Key words: Back pain, Neck pain, Sick leave, Direct costs, Indirect costs

\section{INTRODUCTION}

Between 1995 and 2004, the number of individuals receiving sickness benefits and disability pension increased considerably in Sweden [1]. During this period Neck/shoulder disorders (NSD) and low back disorders (LBD) were two of the predominant reasons for receiving government compensation for sick leave and disability pension [1]. Thus, these disorders represented a major health problem associated with high societal costs [2]. After this period the numbers slowly decreased but have still high national economical importance. There are methodological difficulties to estimate the magnitude of these costs, as the definitions of NSD and LBD are wide and influenced by co-morbidity $[3,4]$. In most cost-of-illness studies on NSD or LBD, the two disorders are not separated or solely one of them are studied, without controlling for a potential influence from the other $[2,5,6]$. Individuals suffering from NSD might cost more than those suffering from LBD or vice versa. Those suffering from concurrent NSD and LBD might also cost more than those having solely NSD or solely LBD. Knowledge about these potential differences in costs is currently lacking. Identifying subjects that have high respectively low economical costs is important in the planning of efficient prevention strategies. The aim of the present study was to analyse if the localization of unspecific back disorders influenced the yearly direct and indirect costs during a five year period; 1996 to 2001.

\section{SUBJECTS}

The present study consisted of subjects from the MUSIC-Norrtälje study, a case-referent study of NSD and LBD performed in 1994-1997, including a follow-up of the same individuals performed in 2000-2001. The response rate of the follow-up was $83 \%(n=2,329)$. The data collection methods and the design of the MUSIC-Norrtälje baseline and follow-up studies have been described in detail elsewhere [7-10]. At baseline, the study base comprised all men and women between 20 and 59 years, who during the study period lived in and did not work outside the community of Norrtälje. The cases were those who sought 
care for NSD or LBD during the same period. For each case, at least one referent was randomly selected from the study base, with respect taken to age and gender. This selection was made with the help of the Population and Housing Register from Statistics Sweden.

For the present study, the number of included subjects was 2,329. Out of these, 272 had given incomplete answers to the questionnaire questions used for classifying each subject into different disorder groups, based on the location and the recurrence of the disorders. Age and gender did not differ between the subjects with incomplete $(n=272)$ and those with complete answers $(n=2,057)$. In the present study, the study group consisted of 2,057 subjects, i.e. all the classifiable cases and referents who participated in both the baseline and the follow-up studies.

\section{METHOD}

\subsection{Data Sources}

Data sources used in the present study were: (1) the MUSIC-Norrtälje baseline study performed 1994 to 1997, (2) the MUSIC-Norrtälje follow-up study, performed 2000 to 2001 with the same subjects as in the MUSIC- Norrtälje baseline study [7-10], (3) Register data on government economic compensation for sickness absence received from the National Social Insurance Board covering the period 1995 to 2001 and linked to each of the 2,057 subjects in the study group, (4) Register data on income and unemployment benefit, received from Statistics Sweden covering the period 1995 to 2001 and linked to each subject in the study group. This study was performed with approval from the ethical research committee at the Karolinska Institutet, Stockholm, Sweden (Karolinska hospital Dnr 03-139).

\subsection{Disorder groups}

For each test occasion, baseline and follow-up, the subjects were classified into one of four groups according to pain and pain-related disability ratings: (1) No NSD and no LBD, (2) Solely LBD, (3) Solely NSD, and (4) Concurrent NSD and LBD, for definitions see below. By combining the results from the baseline and the follow-up 16 groups with and without recurrent disorders were identified. To get a manageable number of groups, these 16 groups were pooled into seven groups with different locations and recurrence of the disorders (Figure 1). One group was free from NSD and LBD at both test occasions, "No Neck/Shoulder or Low Back" and this group was used as a control group in the present study. 
Johan LIWING, Christina WIKTORIN, Wilhelmus JA GROOTEN,

Teresia NYMAN and Magnus SVARTENGREN

Figure 1. Definitions of the six disorder groups with NSD and/or LBD and the control group based on self-reported pain and pain-related disability of the disorders at baseline 1995 to 1996 and follow-up 2000 to 2001. Group 1-3 recurrent disorders, group 4 recurrent disorders with a change of localization, group 5-6 disorders at only one test occasion, and group 7 control group.

\begin{tabular}{|c|c|c|c|c|c|}
\hline & & \multicolumn{4}{|c|}{ 5-YEAR FOLLOW-UP } \\
\hline & & $\begin{array}{c}\text { No } \\
\text { NSD or LBD }\end{array}$ & NSD & LBD & NSD and LBD \\
\hline \multirow{4}{*}{ 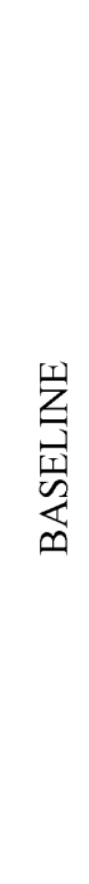 } & $\begin{array}{l}\text { No } \\
\text { NSD } \\
\text { or } \\
\text { LBD }\end{array}$ & 7 & 5 & 5 & 5 \\
\hline & NSD & 6 & 1 & 4 & 4 \\
\hline & LBD & 6 & 4 & 2 & 4 \\
\hline & $\begin{array}{l}\text { NSD } \\
\text { and } \\
\text { LBD }\end{array}$ & 6 & 4 & 4 & 3 \\
\hline \multicolumn{3}{|c|}{$\begin{array}{l}\text { 1. Solely Neck/Shoulder } \\
\text { 2. Solely Low Back } \\
\text { 3. Concurrent Neck/Shoulder \& Low Back } \\
\text { 4. Migrating }\end{array}$} & \multicolumn{3}{|c|}{$\begin{array}{l}\text { 5. Debut } \\
\text { 6. Recovered } \\
\text { 7. No Neck/Shoulder or Low Back (control group) }\end{array}$} \\
\hline
\end{tabular}


NSD was defined on the basis of self-reported level of pain intensity and painrelated disability. Both the baseline and the follow-up questionnaires contained three questions concerning neck/shoulder pain intensity and they were phrased according to von Korff (1992) [11]. The questions covered 1) current pain, 2) worst pain experienced during the previous six months, and 3) average pain during the previous six months. These questions were followed by three questions concerning neck/shoulder pain-related disability [11]. These questions covered the last six months. The three questions concerned how much the pain had affected 1) everyday activities, 2) social and family activities, and 3) ability to work (including domestic work). The rating scale for each of these six questions ranged from 0 to 10 where 0 meant no pain/disability at all and 10 meant pain/disability as bad as it could be. For each subject and each test occasion (baseline and follow-up) a neck/shoulder pain intensity score was constructed using the three questions that concerned neck/shoulder pain intensity. The score was calculated as the sum of the three derived figures on the rating scales and divided by 3 . A neck/shoulder pain-related disability score was constructed in the same manner as the neck/shoulder pain intensity score. The chosen limit for a subject to be considered to have a neck/shoulder disorder was a pain intensity score $\geq 3$ and/or a disability score $\geq 1$.

LBD was defined at both test occasions in a corresponding manner as NSD. A low back pain intensity score and a low back pain-related disability score for each test occasion was constructed using the corresponding three questions concerning low back pain intensity and the three questions concerning low back pain-related disability. The same limits were used for defining low back disorder as for neck/shoulder disorder. The distributions of the pain scores respectively pain-related disability scores concerning the two body regions and the two test occasions were similar.

\subsection{Potential confounders}

Potential confounders were Other diseases besides NSD and LBD, Age, and Gender. Other diseases were defined as physical illnesses or psychological distress experienced at both baseline and follow-up. The questions about physical illnesses concerned five groups of illnesses: cardiovascular, respiratory, gastrointestinal, urogenital, and metabolic illnesses. The questions about psychological distress were assigned a separate group [12]. Subjects were considered as having Other diseases if the same group of physical illnesses or if psychological distress was present at both baseline and follow-up. Subjects were grouped into two different Age groups 1) $<45$ years old and 2) $\geq$ 45 years old (Table 1 ). 
Johan LIWING, Christina WIKTORIN, Wilhelmus JA GROOTEN,

Teresia NYMAN and Magnus SVARTENGREN

Table 1. The number of subjects $(\mathrm{n})$ in the six disorder groups and the control group and the distribution in percent $(\%)$ of sex, age and prevalence of other diseases for the studied subjects $(n=2,057)$ in each group. The same data is shown for the randomly selected referents between 20 and 64 years.

\begin{tabular}{|c|c|c|c|c|}
\hline & Subjects & Sex & Age & Other Diseases $^{a)}$ \\
\hline & (n) & \multicolumn{3}{|c|}{ (\%) } \\
\hline & & Women & $>=45$ & Present \\
\hline All Subjects & 2057 & 60 & 43 & 20 \\
\hline 1. Solely Neck/Shoulder & 100 & $73^{\text {b) }}$ & $33^{\text {b) }}$ & $28^{\mathrm{b})}$ \\
\hline 2. Solely Low Back & 132 & 50 & 41 & 14 \\
\hline $\begin{array}{l}\text { 3. Concurrent Neck/ } \\
\text { Shoulder \& Low Back }\end{array}$ & 321 & $67^{\text {b) }}$ & 52 & $34^{\text {b) }}$ \\
\hline 4. Migrating & 379 & $68^{\mathrm{b})}$ & $40^{\mathrm{b})}$ & $26^{\mathrm{b})}$ \\
\hline 5. Debut & 244 & $63^{b)}$ & 40 & $17^{\mathrm{b})}$ \\
\hline 6. Recovered & 355 & 55 & $40^{\mathrm{b})}$ & $18^{\mathrm{b})}$ \\
\hline $\begin{array}{l}\text { 7. No Neck/Shoulder or Low } \\
\text { Back (control group) }\end{array}$ & 526 & 54 & 47 & 11 \\
\hline Randomly selected referents & 1203 & 58 & 44 & 18 \\
\hline
\end{tabular}

a) Including psychological distress.

b) The proportion was significant different, $\mathrm{p}<0.05$, compared to the control group "No Neck/Shoulder or Low Back".

\subsection{Economical Model}

A "bottom-up" approach was used in the present study [13-17]. To estimate the costs for NSD and LBD several problem areas has to be addressed. First of all, the duration of these disorders varies and they are mostly viewed as recurrent [3]. This makes it suitable to use longitudinal studies with at least two points of measurements for each individual. In the present study, the disorders were examined at two different times, the baseline in 1995 to 1996 and in the followup 2000 to 2001. 
Direct costs were defined as costs for Drug consumption, Health care visits and Ergonomic interventions (Table 2). Records on utilization of these resources were received from self-reports and available in either the baseline or the followup questionnaires. Drug consumption was grouped into 1) Analgesics, 2) Naturopathic preparations and vitamins, and 3) Other drugs. The unit costs for one year and standard dose for Analgesics and Other drugs were taken from the Swedish pharmacy chain Apoteket (sole Swedish retailer). The unit cost for Naturopathic preparations and vitamins was taken from retail stores and standard consumption was applied. Health care visits was grouped into visits to 1) Physician, 2) Physiotherapist and 3) Other caregivers. The unit costs for visits to Physician and Physiotherapist were taken from the Swedish federation of county councils and visits to Other caregivers from interviews with three of the caregivers in Norrtälje. Ergonomic interventions were divided into 1) Technical equipment including work site reconstruction and 2) Ergonomic education. The unit costs for Ergonomic interventions were estimated by the authors (CW, WG). By assuming constant utilization of these resources during the period 1996 to 2001, yearly estimates of the direct costs could be made.

Table 2. Classification of different types of direct costs and their unit cost.

\begin{tabular}{|c|c|}
\hline & Unit Costs \\
\hline Drugs(\%) & Per year \\
\hline $\begin{array}{l}\text { Analgesics } \\
\text { Naturopathic preparations \& vitamins } \\
\text { "Other drugs" b) } \\
\end{array}$ & $\begin{array}{l}\$ 21 \\
\$ 21 \\
\$ 21\end{array}$ \\
\hline Health care visits ${ }^{c}$ & Per visit \\
\hline $\begin{array}{l}\text { Physician } \\
\text { Physiotherapist } \\
\text { "Other caregivers" }\end{array}$ & $\begin{array}{l}\$ 72 \\
\$ 31 \\
\$ 31 \\
\end{array}$ \\
\hline Ergonomic intervention $^{c)}$ & Per year \\
\hline $\begin{array}{l}\text { Technical equipment including work site reconstruction } \\
\text { Ergonomic education }\end{array}$ & $\begin{array}{l}\$ 31 \\
\$ 41\end{array}$ \\
\hline
\end{tabular}

a) Information about utilization of resources was taken at baseline and the questions covered utilization at baseline.

b) "Other drugs" partially contained drugs that could be related to NSD or LBD such as hormones for prevention of osteoporosis.

c) Information about utilization of resources was taken at follow-up and the questions covered the period during the last five years. Utilization of resources was only due to NSD or LBD.

d) Chiropractors, doctor of naprapathy and others, e.g. masseurs.

Indirect costs were estimated by the human capital method and defined as the daily individual salary, times the individual number of sickness absence days, times the percentage of sickness absence [18]. Daily individual salary was 
Johan LIWING, Christina WIKTORIN, Wilhelmus JA GROOTEN,

Teresia NYMAN and Magnus SVARTENGREN

calculated yearly for each subject using yearly income register data (Statistics Sweden). If a subject had a registered income from work, but the estimated daily salary was below two hours of working time at average salary, i.e. $\$ 16.5$, it was viewed as unrealistic. In these few cases, the daily salary of the previous year was used in stead. If no daily salary could be estimated for the first year, 1995 , or was below $\$ 16.5$, a daily salary of $\$ 16.5$ was used. Social taxes, $40 \%$ of the daily salary, were included in the daily salary. Sickness absence days were defined as days with governmentally compensated sickness absence. The number of sickness absence days for each subject was received from sickness absence compensation register data. The government compensated sickness absence days covered sickness benefit and disability pension. Sickness benefit was given when the period absent from work exceeded 14 days, except during the period from January 1, 1997, to April 1, 1998, when this period had to exceed 28 days [19]. This exception was due to a temporary legislative change in the Swedish social security system. Sickness absence days were counted, regardless of the diagnoses on the physician's certificate of illness. If the subject was unemployed at the same time as registered as sickness absent, sickness absence days were not counted. All costs are here presented in 2002 prices and USD using the average exchange rate of 2002 of 9.7067 \$SEK and the Swedish consumer price index to convert all prices to 2002 years' price level.

To be able to identify costs cost due to NSD and LBD, a control group consistently healthy from NSD and LBD was used. A control group was necessary to use when estimating costs due to NSD and LBD since costs can occur due to several different reasons other than NSD and LBD. This control group should be comparable to the disorder groups in all other aspects causing costs than having NSD and/or LBD. Three variables were considered to possibly influence costs: Other diseases, Age, and Gender. To be able to identify these three variables as potential confounding variables, linear regression analyses, were made in spite of the non-normality. Here the control group was used as reference group.

According to confounders of importance, stratified analysis of the indirect respectively the direct costs were done for each disorder group including the control group. Other diseases were always considered as an important confounder. Average individual direct costs for NSD or LBD in the different strata in a disorder group were estimated by subtracting average utilization of resources in each stratum in the control group from estimated utilization of resources in corresponding stratum in the specific disorder group. This difference was then multiplied with the specific unit costs. In the estimation of indirect costs the correlation between sickness-absence and salary was also taken into account. (See appendix for exact calculations of the indirect costs due to NSD and LBD).

In each disorder group the strata were put then together to one, using weighted averages where the weights were estimated using the prevalences among the randomly selected referents in the MUSIC-Norrtälje study and, when possible, 
the prevalences in Sweden using data from Statistics Sweden. The weights (prevalences) for each stratum was multiplied with the average costs for NSD and/or LBD in each disorder group in order go get average costs for the disorder group. The prevalence of women among the randomly selected referents was high in the present study compared to a general Swedish population due to the original design of the MUSIC-Norrtälje study. To adjust for the overrepresentation of women in the present study, each woman was counted as 0.84 woman and each man was counted as 1.22 man in the prevalence estimation. This adjustment gave a gender distribution equal to that of the 2064 -year-old Swedish population. This adjustment was done to get results that are more comparable with other studies. The prevalence of subjects 45 years or older were the same as for the general Swedish population. The prevalence of Other diseases in each disorder group were taken from the referents in the MUSIC-Norrtälje study. 


\section{RESULTS}

\subsection{Direct costs}

Besides Other diseases, Gender proved to be an important confounder. Hence, for estimating direct costs due to NSD and LBD, subjects were stratified based on Gender and on Other diseases. Average yearly direct costs due to NSD or LBD was highest for subjects with concurrent NSD and LBD, i.e. the disorder group "Neck/Shoulder and Low Back", \$174 compared to \$77 and \$66 for individuals with solely NSD or solely LBD, respectively. The average yearly direct costs were $\$ 95$ for subjects with migrating disorders, $\$ 54$ for individuals with a debut of NSD and/or LBD and $\$ 14$ for subjects recovered from NSD and/or LBD (Table 3). Yearly costs for Health care visits seemed to drive the costs in each disorder group. Among these costs, yearly visits to Physiotherapists were the highest in all but two disorder groups.

Table III. Average yearly direct costs for NSD and LBD in each of the six disorder groups. The direct costs in each disorder group are costs above and beyond the costs in the control group and expressed in US dollars (\$).

\begin{tabular}{|c|c|c|c|c|c|c|}
\hline $\begin{array}{l}\text { Average yearly } \\
\text { direct costs (\$) }\end{array}$ & $\begin{array}{l}\text { Solely } \\
\text { Neck/ } \\
\text { Shoulder }\end{array}$ & $\begin{array}{c}\text { Solely } \\
\text { Low Back }\end{array}$ & $\begin{array}{c}\text { Concurrent } \\
\text { Neck/ } \\
\text { Shoulder \& } \\
\text { Low Back }\end{array}$ & Migrating & Debut & Recovered \\
\hline $\begin{array}{l}\text { Yearly Costs for } \\
\text { Drugs }\end{array}$ & 6 & 2 & 8 & 6 & 2 & 3 \\
\hline Analgesics & 4 & 2 & 6 & 4 & 1 & 1 \\
\hline $\begin{array}{l}\text { Naturopathic } \\
\text { preparations \& } \\
\text { vitamins }\end{array}$ & 2 & 0 & 1 & 1 & 0 & 0 \\
\hline Other drugs & 0 & 0 & 1 & 1 & 0 & 1 \\
\hline $\begin{array}{l}\text { Yearly Costs for } \\
\text { Health Care Visits }\end{array}$ & 62 & 58 & 156 & 83 & 47 & 10 \\
\hline Physician & 20 & 19 & 40 & 23 & 13 & 2 \\
\hline Physiotherapist & 22 & 25 & 77 & 32 & 26 & 4 \\
\hline Other caregivers & 21 & 15 & 39 & 28 & 8 & 5 \\
\hline $\begin{array}{l}\text { Yearly Costs for } \\
\text { Ergonomic } \\
\text { Interventions }\end{array}$ & 8 & 6 & 10 & 7 & 5 & 1 \\
\hline $\begin{array}{l}\text { Technical } \\
\text { equipment }\end{array}$ & 5 & 3 & 5 & 4 & 2 & 1 \\
\hline $\begin{array}{l}\text { Ergonomic } \\
\text { education }\end{array}$ & 3 & 4 & 6 & 4 & 3 & 0 \\
\hline $\begin{array}{l}\text { TOTAL } \\
\text { Yearly Direct Costs }\end{array}$ & 77 & 66 & 174 & 95 & 54 & 14 \\
\hline
\end{tabular}




\subsection{Indirect costs}

Age and Other diseases proved to be important confounders. Hence, for estimating indirect costs for NSD and LBD, subjects were stratified based on Age and on Other diseases. Average yearly indirect costs due to NSD and LBD were highest for individuals with concurrent NSD and LBD, i.e. the disorder group "Neck/Shoulder and Low Back", \$1,300 in 1996 and \$5,800 in 2001 (Figure 2). Furthermore, the average individual increase in costs was three to four times higher for this disorder group than for the two groups with solely NSD or solely LBD during the observed period (Figure 2). The recovered group seemed to have lowered their costs during the period, and in fact had lower costs than the healthy control group. This "negative" cost could be interpreted as a result of the variance in the data.

Figure 2. Average indirect costs 1996-2001 in the six disorder groups with NSD or LBD. The indirect costs in each disorder group are costs above and beyond the costs in the control group and expressed in US dollars (\$).

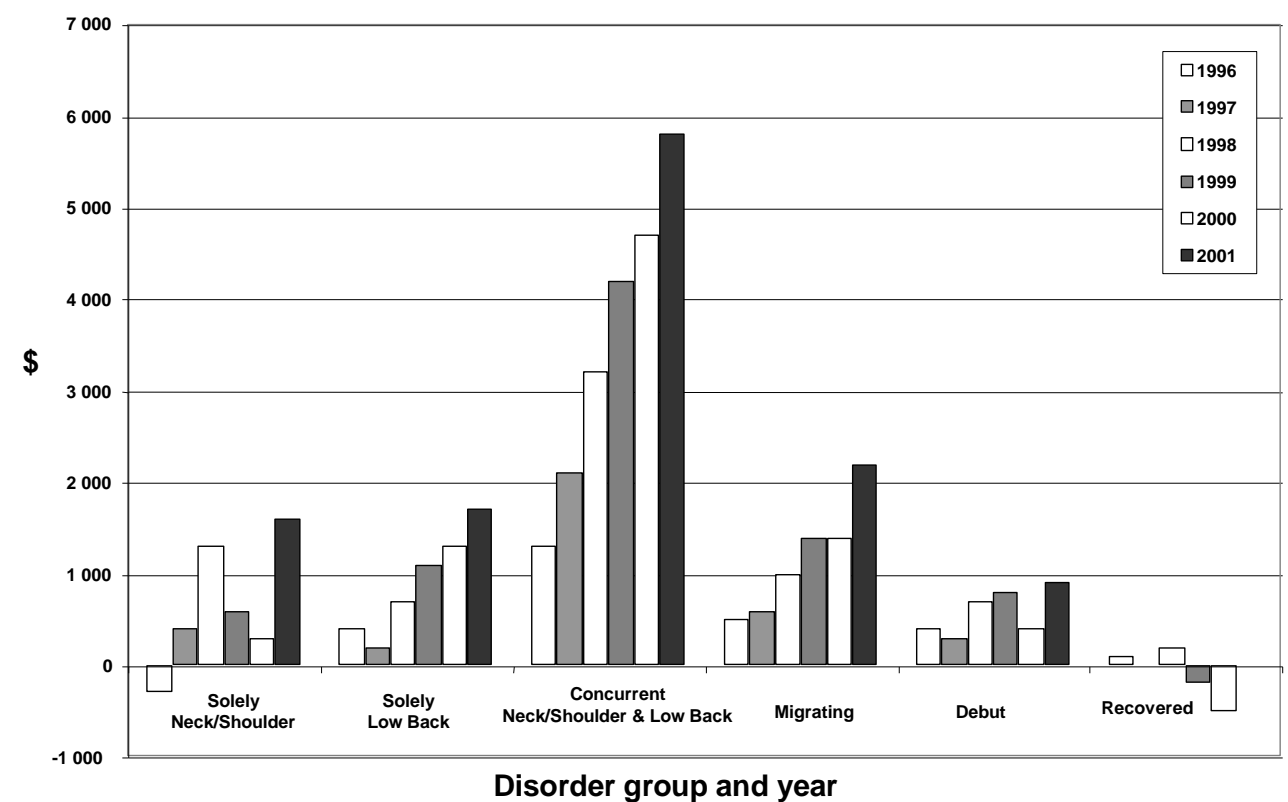

\subsection{Total average costs}

Total average costs are the sum of the direct costs and the indirect cost. For all years, 1996-2001, total average costs were highest for the disorder group "Neck/Shoulder and Low Back" and was for the year 2001, \$6.000. The direct costs were around $4 \%$ to $16 \%$ of the total costs depending on the year, with an average value of $8 \%$ considering all disorder groups and years. 
Johan LIWING, Christina WIKTORIN, Wilhelmus JA GROOTEN,

Teresia NYMAN and Magnus SVARTENGREN

\section{DISCUSSION}

The indirect costs were around tenfold larger, than the direct costs. This is in accordance with other studies $[2,5,6,20]$. For the Netherlands, Borghouts et al estimated the direct medical costs for patients with neck pain to $23 \%$ and the indirect non-medical costs to $77 \%$ of the total costs [6]. In another study, van Tulder et al estimated these percentages for low back pain to $7 \%$ and $93 \%$, respectively [5]. For Sweden, Hansson \& Hansson found that the direct costs mounted for approximately $7 \%$ and the indirect costs for $93 \%$ of the total costs in a two year period, between 1994 and 1995 [2]. Both in the study by Hansson \& Hansson and the present study a bottom-up approach was used. Hansson \& Hansson reported the total average individual costs in 2001 to 18.666 Euros. One explanation to these much higher costs compared to the present study could the differences in the inclusion criteria between the two studies. In the study by Hansson \& Hansson, the subjects included had to be sick-listed at least 28 consecutive days. This approach increase precision but it is less sensitive for the societal problem of low back pain, as most of the individuals are not sick-listed at all [3]. In the present study, an unspecific back pain population was used which probably represents the majority of back pain patients [3]. Furthermore, no control group was used in the study by Hansson \& Hansson. The use of a control group might be of less importance, when costs are driven by a specific disease alone or at least to a very high degree. This is probably not the case for unspecific low back or neck/shoulder pain, since the costs for these types of disorders could be driven by other factors, e.g. attitudes to sick-leave as well. The use of a control group to solve these kind of problems is the only acceptable approach, but not common in economic evaluations.

Since the indirect costs were around tenfold the direct costs, it is vital to prevent subjects with NSD and/or LBD from having absence days due to sick leave. One method could be the use of efficient treatments, in order to recover subjects from their disorders. To be able to give the correct treatment, further research is needed for finding the underlying source to the pain. Another alternative is to reorganize the workplace so that patients can continue their work despite of their disorders.

The present study indicated that subjects suffering from concurrent NSD and LBD act as the most prominent cost drivers for the direct as well as the indirect costs. These subjects had higher consumption of health care and more sickness absence. To our knowledge, the result that subjects suffering from recurrent NSD in combination with recurrent LBD have considerably higher costs than individuals suffering from solely recurrent NSD or solely recurrent LBD has not been reported previously. Average costs for individuals suffering from solely NSD or from solely LBD seemed to be quite similar. Subjects who recovered from NSD and/or LBD during the period seemed to have the lowest costs. This indicates that there is a potential for lowering average costs per individual if 
effective rehabilitation or treatment programs are used on those subjects at risk for persistent disorders. Subjects with a debut of NSD or LBD had similar costs as subjects with solely NSD or solely LBD. Thus, prevention programs should be focused on healthy subjects, primary prevention. Secondary and tertiary prevention seems to be important to prevent subjects from getting recurrent and concurrent NSD and LBD. Probably, caregivers should keep their focus on these individuals. Further studies are necessary to investigate not only which medical or ergonomic interventions are associated with a recovery from NSD and/or LBD, but also the cost-effectiveness of these interventions should be estimated. Since the costs for individuals suffering from concurrent NSD and LBD have risen sharply from 1996 to 2001, the urge for these studies is high. Furthermore, the rationales for this large increase in average costs during these years need to be studied more deeply. Societal factors, e.g. fluctuations of the market and unemployment rates, should then be taken into account. Analyses using different economic models to explore this area are currently under process.

In the present study, two test occasions were used as the authors viewed NSD and LBD as recurrent disorders. To our knowledge, this has not been done previously in economic modelling of NSD and/or LBD. The differences in costs between the subjects with concurrent NSD and LBD compared to the other groups should not has been as clear if the data was analysed on base of the presence of a combination of these two disorders at baseline only.

The cost-estimates for drugs and ergonomic interventions due to NSD and/or LBD were crude, as they were based on self-reports and only one test occasion was used. Moreover, the estimates for the total direct costs should be interpreted with care, since no data was available for the health care costs due to surgery, home nursing, travel costs, out-of-pocket medical costs, etc. [21]. However, as the direct costs were comparably low, the influence of these uncertain estimations on the total costs should be marginal. The indirect costs were underestimated, since short-term absence from work, i.e. less than 14 days, was not included in the present study.

The subjects aged six years during the study period. In theory, this could explain the increase in indirect costs in nearly all disorder groups. However, since aging was valid for the control group as well, this problem was corrected for.

Concisely, the present study showed that the highest direct and indirect costs were related to subjects with concurrent NSD and LBD over an extended period of time. Moreover, the largest increase in costs between 1996 and 2001 was seen in this group. Further studies are required to identify which characteristics in work environment or in life style factors that causes recurrent and concurrent NSD and LBD. Additionally, studies should be focused on the identification of the contributive factors that enables workers to continue their work despite the presence of pain or disability, and the factors that promotes the return to work. 
Johan LIWING, Christina WIKTORIN, Wilhelmus JA GROOTEN,

Teresia NYMAN and Magnus SVARTENGREN

\section{ACKNOWLEDGEMENTS}

We would like to thank the Department of Occupational and Environmental Health, the Stockholm City Council, and the Swedish Council for Working Life and Social Research for financial support. We would also like to thank Associate Professor Magnus Johannesson at the Stockholm School of Economics and Associate Professor Lena Ekenvall at the Department of Occupational and Environmental Health, Stockholm County Council, for valuable comments and critical remarks. Finally, we would like to thank Linda Norrman for her help with the statistical analyses.

\section{REFERENCES}

[1] National Social Insurance B. Nybeviljade förtidspensioner/sjukbidrag 2002 [in swedish]. In: Statistical report is-i. Stockholm: National Social Insurance Board; 2003.

[2] Hansson EK, Hansson TH. The costs for persons sick-listed more than one month because of low back or neck problems. A two-year prospective study of swedish patients. Eur Spine J 2005; 14:337-345.

[3] Waddell G. The back pain revolution. Edinburgh: Churchill Livingstone; 1998.

[4] Nordin M, Hiebert R, Pietrek M, Alexander M, Crane M, Lewis S. Association of comorbidity and outcome in episodes of nonspecific low back pain in occupational populations. J Occup Environ Med 2002; 44:677-684.

[5] van Tulder MW, Koes BW, Bouter LM. A cost-of-illness study of back pain in the netherlands. Pain 1995; 62:233 -240.

[6] Borghouts JA, Koes BW, Vondeling H, Bouter LM. Cost-of-illness of neck pain in the netherlands in 1996. Pain 1999; 80:629-636.

[7] Wigaeus Tornqvist E, Kilbom A, Vingard E, Alfredsson L, Hagberg M, Theorell T, et al. The influence on seeking care because of neck and shoulder disorders from work-related exposures. Epidemiology 2001; 12:537-545.

[8] Vingard E, Alfredsson L, Hagberg M, Kilbom A, Theorell T, Waldenstrom M, et al. To what extent do current and past physical and psychosocial occupational factors explain care-seeking for low back pain in a working population? Results from the musculoskeletal intervention center-norrtalje study. Spine 2000; 25:493-500. 
[9] Grooten WJA, Wiktorin C, Norrman L, Josephson M, Wigaeus Tornqvist E, Alfredsson L. Seeking care for neck/shoulder pain: A prospective study of work-realated risk factors in a healthy population. J. Occup. Environ. Med. 2004; 46:138-146.

[10] Pernold G, Mortimer M, Wiktorin C, Tornqvist EW, Vingard E. Neck/shoulder disorders in a general population. Natural course and influence of physical exercise: A 5-year follow-up. Spine 2005; 30:E363E368.

[11] Von Korff M, Ormel J, Keefe FJ, Dworkin SF. Grading the severity of chronic pain. Pain 1992; 50:133-149.

[12] Waldenstrom M, Theorell T, Ahlberg G, Josephson M, Nise P, Waldenstrom K, et al. Assessment of psychological and social current working conditions in epidemiological studies: Experiences from the music-norrtalje study. Scand J Public Health 2002; 30:94-102.

[13] Rice DP. Estimating the cost of illness. In: Health economics series. Washington: U.S. Departement of Health, Education and Wellfare; 1966.

[14] Tolpin HG, Bentkover JD. Economic cost of illness: Decision-making applications and practical considerations. Adv. Health Econ. Health Serv. Res. 1983; 4:165-198.

[15] Hodgson TA, Meiners MR. Cost-of-illness methodology: A guide to current practices and procedures. Milbank Mem Fund Q Health Soc 1982; 60:429-462.

[16] Scitovsky AA. Estimating the direct costs of illness. Milbank Mem Fund $Q$ Health Soc 1982; 60:463-491.

[17] Rice DP. Cost-of-illness studies: Fact or fiction? Lancet 1994; 344:1519-1520.

[18] Koopmanschap MA, Rutten FF, van Ineveld BM, van Roijen L. The friction cost method for measuring indirect costs of disease. J Health Econ 1995; 14:171-189.

[19] Statistics Sweden. En longitudinell database kring utbildning, inkomst och sysselsättning (LOUISE) 1990-1999. In: Bakgrundsfakta till arbetsmarknads och utbildningsstatistiken. Örebro: Statistics Sweden; 2002. 
Johan LIWING, Christina WIKTORIN, Wilhelmus JA GROOTEN,

Teresia NYMAN and Magnus SVARTENGREN

[20] Ekman M, Johnell O, Lidgren L. The economic cost of low back pain in sweden in 2001. Acta Orthop 2005; 76:275-284.

[21] Mittendorf T, Merkesdal S, Huelsemann JL, von der Schulenburg JM, Zeidler H, Ruof J. Implementing standardized cost categories within economic evaluations in musculoskeletal diseases. Eur J Health Econ 2003; 4:43-49.

\section{APPENDIX}

For calculating indirect costs using the bottom-up model with a control group, four assumptions were made for describing the behaviour of individuals when they had recovered from back-pain symptoms. (1) Recovered subjects would not change their daily salary, $S_{\text {Back-pain. }}$ (2) The number of days currently at sickleave, $D_{\text {Back-pain, would change to the average value in the corresponding control }}$ group, $D_{\text {Symptom free }}=D_{\text {Control group. }}$ (3) The standard deviation for sick-leave days was assumed to be the same as the for control group, $\sigma\left[D_{\text {symptom free }}\right]=\sigma\left[D_{\text {control }}\right.$ group]. (4) The correlation coefficient between daily salary and sick-leave days was assumed to be equal to the value for the control group, $\rho\left[D_{\text {Symptom free, }}, S_{\text {Back- }}\right.$ pain $]=\rho\left[D_{\text {Control group }}, S_{\text {Control group }}\right]$. Using these four assumptions, average indirect costs due to back-pain in each strata could be expressed as:

Estimatedindirect costsfor back - pain in each strata $=C_{i}$

$=E\left(D_{\text {Back-pain }}-D_{\text {Symptomfree }}\right) S_{\text {Back-pain }}=$

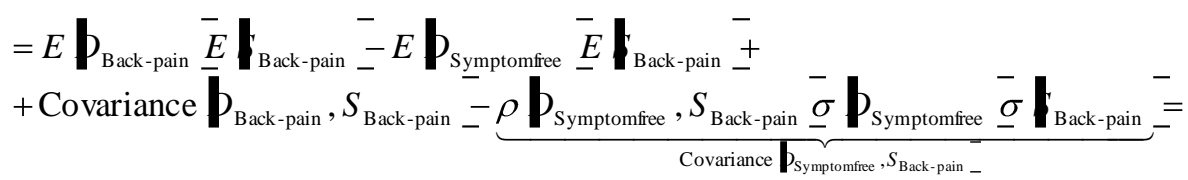

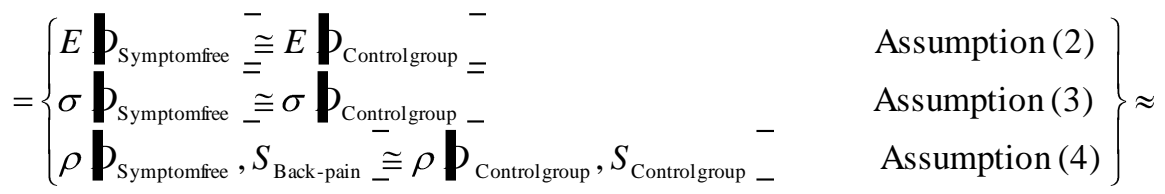

$\approx \underbrace{E P_{\text {Back-pain }}-E}_{\text {Difference in average days absent from work times the average salary }} \mathrm{P}_{\text {Controlgroup } Z E}-$

$\underbrace{+\operatorname{Cov} \mathrm{P}_{\text {Back-pain }}, S_{\text {Back-pain }}-\rho \mathrm{P}_{\text {Controlgroup }}, S_{\text {Controlgroup }} \underline{\sigma} \mathbf{P}_{\text {Controlgroup }} \underline{\sigma} \mathbf{s}_{\text {Back-pain }}^{-}}$ 
Hence, indirect costs were estimated for each stratum by taken the difference in average days absent from work between the group with back-pain and without back-pain and multiply this by the salary in the group with back-pain. Furthermore, adjustments for indirect costs due to correlations between sickness absence days and daily salary were made. A negative correlation between sickness absence days and salary has previously been reported for back-pain patients [2]

In each disorder group the strata were put then together to one, using weighted averages where the weights were estimated using the prevalences among the randomly selected referents in the MUSIC-Norrtälje study and, when possible, the prevalences in Sweden using data from Statistics Sweden. The weights (prevalence) for each stratum was multiplied with the average costs for NSD and/or LBD in each disorder group in order go get average costs for the disorder group according to:

Estimatedindirect costsfor back - pain in a disordergroup $=\sum_{\mathrm{i}=\text { All stratas in each disorder group }}$

where $\sum_{\mathrm{i}=\text { Allstratas in each disorder group }} \mathrm{w}_{\mathrm{i}}=1$ 